\title{
CLOVER RESPONSE TO INOCULATION AND PELLETING ON TE ANAU SOILS
}

\author{
W. L. Lowther and I. R. McDonald \\ Invermay Agricultural Research Centre, Mosgiel
}

Summary

Results are given for trials investigating the effects of inoculation and pelleting on the establishment of white clover oversown in autumn 1971 and 1972.

In the absence of inoculation, few plants established. Inoculation at the normal commercial rate increased the percentage of healthy plants but establishment was still low, Pelleting increased establishment.

In both years, a commercially prepared "triplecote" pellet gave better seedling establishment than pellets prepared with methyl cellulose adhesive. In the one trial conducted in 1972, pellets prepared with gum arabic adhesive and coated with lime or Gafsaphosphate/ dolomite were as effective as commercial "triplecote" pellets in increasing clover establishment.

\section{INTRODUCTION}

IN THE Te Anau area, the Lands and Survey Department has been carrying out large-scale land development by oversowing clover and grass seed into the undisturbed natural vegetation. Establishment of clover in this area is dependent on inoculation of the clover seed with rhizobia prior to sowing (During et al., 1962; Cullen 1964). During et al. (1963) commented that, as the percentage of healthy plants arising from inoculated seed was low, these was room for improvement in inoculation techniques. Their attempts to improve the establishment of clovers by pelleting the seed after inoculation were not successful.

The present trials were designed to reinvestigate the effects of inoculation and pelleting using pellets prepared by the method of Hastings (1964) and commercially prepared "triplecote" pellets.

\section{EXPERIMENTAL}

Two trials were laid down in the Te Anau area in autumn 1971 and 1972. In each year, one trial was oversown on an unimproved browntop (Agrostis tenuis) /hard tussock (Festuca novaezealandiae) site and the other on to bracken (Pteridium aquilinum var. esculentum). In both years results from the two sites were 
similar and therefore only the results from the browntop/hard tussock site are reported in this paper. The trial site was situated adjacent to the T.e Anau - Manapouri road on a Monowai yellow-brown loam of $\mathrm{pH}$ 5.3. Vegetation consisted of browntop, hard tussock, flatweeds and native herbs.

TRIAL $1-1971$

The trial consisted of the following treatments arranged in four randomized blocks. The seed used in all treatments was of 'Grasslands Huia' white clover (Trifolium repens).

\section{Seed Treatments}

(1) Untreated clover seed.

(2) Normal commercial inoculation (Adlife peat inoculant) no pellet.

(3) 5 times normal inoculation $(x 5 \mathrm{~N})-$ no pellet.

(4) Normal inoculation + lime pellet (methyl cellulose adhesive).

(5) Commercial "triplecote" pellet (Coated Seed Ltd., Christchurch).

Normal inoculation supplied 1,000 rhizobia per seed on March 10 and 1,900 rhizobia per seed on March 24. Commercial "triplecote" pellets contained 4,100 rhizobia per seed 1 day after pre paration and 700 rhizobia 15 days after preparation.

\section{Storage Treatments}

Two storage periods from inoculation to sowing were compared. Seed was stored at 10 to 15 " C.

(1) Sown 2 to 3 days after inoculation.

(2) Sown 16 to 17 days after inoculation (with the exception of $X 5 \mathrm{~N}$ inoculation).

A basal dressing of $700 \mathrm{~kg} / \mathrm{ha}$ molybdic superphosphate, reverted with $700 \mathrm{~kg} / \mathrm{ha}$ lime, was applied on March 11. White clover seed was broadcast at $10 \mathrm{~kg} / \mathrm{ha}$ on March 12 and March 26. At the first sowing, weather conditions were fine and sunny with a dry soil surface; at the second sowing the sky was overcast and the soil damp. 
The effectiveness of the various inoculation and pelleting treatments was measured by recording the percentage of healthy clover seedlings 6 months after sowing. On April 26, 20 seedling clovers in each plot were pegged at random with wire pegs and the number healthy recorded on September 23.

\section{TRIAL $2-1972$}

The trial consisted of the following treatments arranged in four randomized blocks.

\section{Seed Treatments}

(1) Untreated white clover seed.

(2) Commercial "triplecote" pellets.

(3) Normal commercial inoculation $(\mathrm{N}) \rightarrow$ no pellet.

(4) $\mathrm{N}+$ gum arabic + lime pellet.

(5) $\mathrm{N}+$ methyl cellulose + lime pellet.

(6) $\mathrm{N}+$ gum arabic + Gafsa-phosphate/dolomite pellet.

(7) $\mathrm{N}+$ methyl cellulose + Gafsr-phosphate/dolomite pellet.

Normal inoculation (Rhizocote) supplied 900 rhizobia/seed on March 2 and 2,300 rhizobia/seed on March 14. Commercial "triplecote" pellets contained 230 rhizobia/seed 17 days after preparation.

\section{Storage Treatments}

With treatments (3) to (7) two storage periods from inoculation to sowing were compared:

(1) Seed sown 1 day after inoculation.

(2) Seed sown 13 days after inoculation.

Commercial "triplecote" pellets were sown 17 days after inoculation..

A basal dressing of $700 \mathrm{~kg} / \mathrm{ha}$ molybdic superphosphate was applied on March 9, and $5 \mathrm{~kg} / \mathrm{ha}$ of white clover seed was broadcast on March 15. The weather was fine and warm and the soil surface was dry. On May 5, 40 seedling clovers in each plot were pegged at random and the number healthy recorded on June 23. 
TRIAL 1 1971

\section{RESULTS}

\section{First Sowing}

It is clear from the results (Table 1) that inoculation is essential for white clover establishment in this area. In the absence of inoculation few seedlings were healthy.

TABLE 1: EFFECT OF INOCULATION, PELLETING, AND STORAGE PERIOD ON ESTABLISHMENT OF WHITE CLOVER - 1971

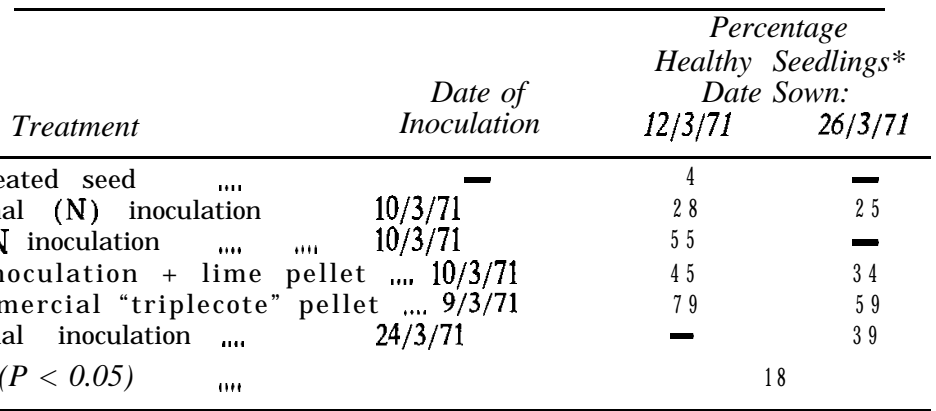

*Percentage of pegged seedlings healthy on 23/9/71.

Inoculating the seed at the normal commercial rate, and sowing within 2 days, increased the percentage of healthy plants to $28 \%$. Increasing the inoculation level to $\mathrm{x} 5$ normal resulted in a further increase' in the percentage of healthy plants.

The apparent increase in the percentage of healthy plants from lime pelleting was not significant. In contrast, $79 \%$ of seedlings were healthy in the commercial "triplecote" pelleting treatment and this percentage of healthy plants was significantly higher than in any other treatment.

\section{Second Sowing}

As with the first sowing, the "triplecote" pellet treatment had a higher percentage of healthy seedlings than inoculated or inoculated/lime pelleted treatments. There was no significant difference between inoculated and inoculated/lime pelleted seed.

The present results indicate a superiority of commercial "triplecote" pellets over inoculated or inoculated/lime pelleted seed.

TRIAL $2-1972$

As in 1971, there was a virtual establishment failure when the seed was not inoculated (Table 2), and inoculation caused little 
TABLE 2: EFFECT OF INOCULATION, PELLETING, AND STORAGE PERIOD ON ESTABLISHMENT OF WHITE CLOVER 1972

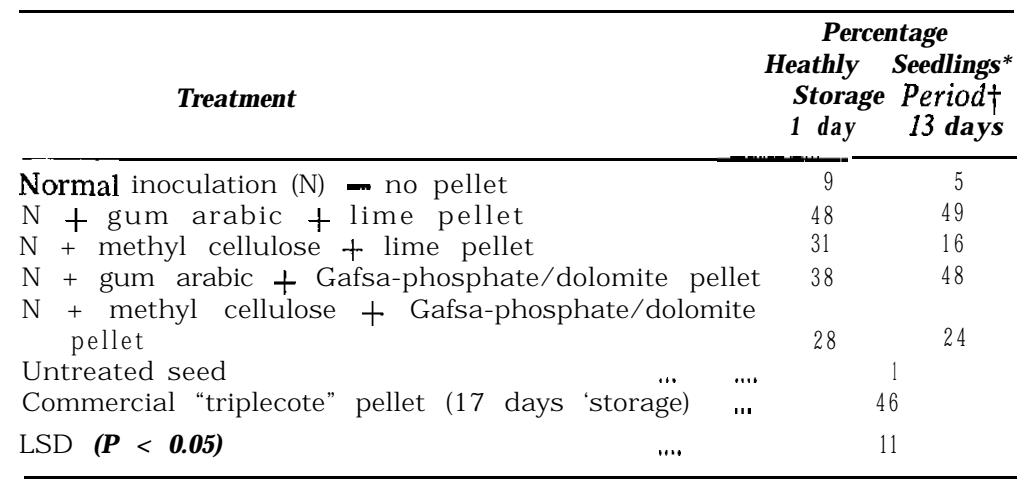

*Percentage of pegged seedlings healthy on $23 / 6 / 72$.

$\uparrow$ All seed sown on $15 / 3 / 72$.

improvement. In contrast $46 \%$ of seedlings were healthy in the "triplecote" pellet treatment. Also as in 197.1, there was a higher percentage of healthy plants in the "triplecote" pelleting treatment than in pelleting treatments (lime or Gafsa/dolomite) prepared with methyl cellulose adhesive.

Results from the pelleting materials $\mathbf{x}$ adhesives comparison indicated a clear superiority of gum arabic adhesive over methyl cellulose for both storage periods $(\mathrm{P}<0.01)$. There was no significant difference in the percentage of healthy plants between the lime and Gafsa/dolomite pelleting materials. With pellets prepared with gum arabic adhesive and sown after 1 day, the apparent reduction with Gafsa/dolomite pelleting compared with lime pelleting just failed to reach significance. With gum arabic/ lime pellets the percentage of healthy plants was similar to that obtained with "triplecote" pellets.

\section{DISCUSSION}

Because of the low nitrogen status of these soils, seedlings will not survive unless effectively nodulated, as shown by the poor establishment from untreated seed. Consequently, the percentage healthy plants could be taken as a measure of the percentage of seedlings nodulated. However, even inoculation at the normal commercial rate was not particularly effective in promoting the establishment of white clover under autumn oversowing conditions. Inoculated seed was sown after a minimum storage period of one or two days to simulate farming practice. Laboratory trials 
have indicated a very rapid decline in the number of viable rhizobia on the seed in the first 24 hours after inoculation (Lowther, unpublished results). This decline could be expected to be accentuated under field conditions (Hely, 1965). The rapid decline in numbers of viable rhizobia would explain the poor results from seed inoculated but not pelleted.

Although widely recommended in Australia (Brockwell, 1963), pelleting the seed after inoculation has been relatively uncommon in Otago/Southland. Hastings and Drake (1962, 1963) have claimed that pelleting of inoculated clover seed is beneficial. However, field trials have failed to substantiate these claims (Cullen and Ludecke, 1966; Adams and Lowther, 1970). The poor results in these reported trials could have been due to inferior inoculants (Lowther et al., 1970). From the present results, it is clear that pelleting is essential for optimum establishment of oversown white clover. A further series of similar trials at other sites in tussock grasslands substantiate these results (Lowther and McDonald, unpublished results). At other sites, a positive linear relationship has been shown between the percentage of healthy seedlings and dry matter production in the first year (Lowther and McDonald, unpublished results). Therefore, clover over-sowing treatments that increase the establishment of seedlings can be expected to increase clover production at least in the first year. Conversely, it will be possible to reduce the seeding rate of effectively pelleted seed and still obtain satisfactory clover establishment.

The present trials have indicated a clear superiority of a commercially prepared "triplecote" pellet over the normally recommended lime or Gafsa-phosphate/dolomite pellet prepared with methyl cellulose as an adhesive (Hastings and Drake, 1962, 1963). Gum arabic proved more effective than methyl cellulose as an adhesive and pellets prepared with gum arabic were as: effective in aiding establishment of white clover as commercial "triplecote" pellets. However, until results are available from several other trials assessing pelleting materials and adhesives under a wider range of environments, "triplecote" pellets are recommended for oversowing.

\section{ACKNOWLEDGEMENTS}

The writers would like to thank Mrs H. Patrick for her assistance with the laboratory and field work. 


\section{REFERENCES}

Adams, A. F. R.; Lowther, W. L., 1970: N.Z. $J l$ agric. Res., 13: 242-51.

Brockwell, J., 1963: World Crops, 15: 334-8.

Cullen, N. A., 1964: Proc. N.Z. Grassld Ass., 26: $109-14$.

Cullen, N. A.; Ludecke, T. E., 1966: Proc. N.Z. Grassld Ass., 28: 96-104.

During, C.; Cullen, N. A.; Bennett, G. M., 1962: N.Z. $I l$ agric. Res., 5: $278-93$

During, C.; Cullen, N. A.; Mountier, N. S., 1963: N.Z. Il agric. Res., 6: 416-31.

Hastings, A., 1964: Proc. N.Z. Grassld Ass., 26: 102-8.

Hastings, A.; Drake, A. D., 1962: N.Z. II Agric., 104: 330-3.

Hastings, A.; Drake, A. D., 1963: N.Z. II Agric., 106: 463-8.

Hely, F. W., 1965: Aust. J. agric. Res., 16: 575-89.

Lowther, W. L.; McDonald, I. R.; Cullen, N. A., 1970: Tussock Grassld \& Mount. Lands Inst. Rev., 20: 84-9. 